\title{
AETIOLOGY AND OUTCOME OF FEVER IN PREGNANCY- AN OBSERVATIONAL STUDY
}

\author{
Pundir Seema1, Khatuja Ritu², Mahajan Puneeta ${ }^{3}$,Sarda Nivedita4 ${ }^{4}$ Rai Swati5, Singhal Mohita ${ }^{6}$
}

${ }^{1}$ Specialist, Department of Obstetrics and Gynaecology, Dr. Baba Saheb Ambedkar Medical College and Hospital, Rohini, Delhi. ${ }_{2}^{2}$ Assistant Professor, Department of Obstetrics and Gynaecology, Dr. Baba Saheb Ambedkar Medical College and Hospital, Rohini, Delhi. ${ }^{3}$ Consultant (Medical Director), Department of Obstetrics and Gynaecology, Dr. Baba Saheb Ambedkar Medical College and Hospital, Rohini, Delhi.

${ }^{4}$ Professor, Department of Obstetrics and Gynaecology, Dr. Baba Saheb Ambedkar Medical College and Hospital, Rohini, Delhi. ${ }_{5}^{5}$ Senior Resident, Department of Obstetrics and Gynaecology, Dr. Baba Saheb Ambedkar Medical College and Hospital, Rohini, Delhi. ${ }^{6}$ Senior Resident, Department of Obstetrics and Gynaecology, Dr. Baba Saheb Ambedkar Medical College and Hospital, Rohini, Delhi. ABSTRACT

\section{BACKGROUND}

Fever is the most common presentation of any infection, which can lead to grave prognosis of maternal and foetal outcome if not managed timely. So, this study was conducted to find out the aetiology and outcomes of fever in pregnant women.

\section{MATERIALS AND METHODS}

An observational study was conducted in Dr. BSAMCH, New Delhi. A total of 180 women admitted with fever during pregnancy from June 2016 to September 2016 were included in the study and managed according to hospital protocol. The aetiology, maternal and neonatal outcomes were noted and evaluated. Results were analysed on excel sheet.

\section{RESULTS}

Out of 180 women $33.33 \%$ were diagnosed with typhoid, $25 \%$ had viral fever, $22.23 \%$ with dengue, $11.6 \%$ with UTI, $5.56 \%$ with malaria and $0.05 \%$ with chikungunya. Approximately, 2.23\% women had both typhoid and dengue. After treatment, 56.66\% $(n=102)$ of women were discharged in good foetal well-being condition. Twenty three percentage $(n=42)$ women had full-term normal vaginal delivery, $12.23 \%(n=22)$ had preterm vaginal delivery and $7.78 \%(n=14)$ underwent caesarean section. Two dengue patients had intrauterine foetal demise and they expired in postpartum period. Eleven neonates from preterm delivery required NICU admission.

\section{CONCLUSION}

The common causes of fever in pregnancy was typhoid, dengue and viral fever. Dengue fever was most fatal of all aetiologies. So rational and individualised approach in managing these patients with low threshold to admit them could be life saving for both mother and foetus.

\section{KEYWORDS}

Pregnancy, Fever, Maternal Outcome, Foetal Outcome.

HOW TO CITE THIS ARTICLE: Seema P, Ritu K, Puneeta M, et al. Aetiology and outcome of fever in pregnancy- an observational study. J. Evolution Med. Dent. Sci. 2018;7(15):1898-1900, DOI: 10.14260/jemds/2018/427

\section{BACKGROUND}

Pregnancy leads to a lot of changes in women's body. It is a state of lower immunity in order to accept a foetus, which is foreign to her. Simultaneously, this lead to the altered susceptibility and severity for infectious disease in pregnancy. Fever is the most common presentation of any infection. Mother and foetus both are affected by the infection as well as the fever. As India being a country of tropical areas and very prone for epidemics of various diseases, thus we have conducted an observational study to find out the aetiology and outcome of fever in women in antenatal period that required admission.

\section{MATERIALS AND METHODS}

An observational study was conducted in a tertiary health care centre in North Delhi region. All women with fever in

'Financial or Other Competing Interest': None.

Submission 26-02-2018, Peer Review 23-03-2018,

Acceptance 29-03-2018, Published 09-04-2018.

Corresponding Author:

Dr. Mahajan Puneeta,

Consultant (Medical Director),

Department of Obstetrics and Gynaecology,

Dr. Baba Saheb Ambedkar Medical College and Hospital, Rohini, Delhi.

E-mail: puneetamahajan@gmail.com

DOI: $10.14260 /$ jemds/2018/427

\section{(c) (1) $(9)$} antenatal period who were admitted from June 2016 to September 2016 were included in the study. Women having sign of septicaemia or chorioamnionitis had been excluded from the study. A total of 180 women were admitted with history of fever in antenatal period. Illness history, clinical examination and clinical evaluation were recorded. A series of tests including fever profile, blood tests, urine tests and ultrasound were conducted and management done according to hospital protocol. Results were analysed on the spread excel sheet.

\section{RESULTS}

Most of the women were from suburban area of North Delhi. All of the women belonged to low socioeconomic status. Almost, $41 \%$ of women who were in the age group of $20-25$ years. Only $28.89 \%$ of women were primigravida and rest were multigravidas. There were $10.46 \%(n=19)$ of women in $1^{\text {st }}$ trimester, $30.32 \%(n=55)$ of women in $2^{\text {nd }}$ trimester and $58.88 \%(n=106)$ of women in 3 rd trimester. All women were initially started with empirical management followed by specific management according to the result of the investigations. Duration of stay were ranging from 2 days to 11 days with a mean duration of 6 days. Around $68 \%$ of women stayed for 2 to 7 days, $26.78 \%$ stayed for more than 7 days and $5.22 \%$ of women stayed for less than 2 days. A total 
of $33.33 \%(n=60)$ of women were diagnosed with typhoid, $25 \%(n=45)$ with viral fever, $22.23 \%(n=40)$ with dengue, $11.6 \%(n=20)$ with UTI, $5.56 \%(n=10)$ with malaria and $0.05 \%(n=1)$ with chikungunya. Approximately, $2.23 \%(n=4)$ women had both typhoid and dengue (Table 1).

\begin{tabular}{|c|c|c|}
\hline Cause of Fever & Number of Patients & \% of Patients \\
\hline Typhoid & 60 & 33.3 \\
\hline Other Viral Fevers & 45 & 25.0 \\
\hline Dengue & 40 & 22.2 \\
\hline UTI & 20 & 11.1 \\
\hline Malaria & 10 & 5.6 \\
\hline Typhoid + Dengue & 4 & 2.2 \\
\hline Chikungunya & 1 & 0.6 \\
\hline \multicolumn{2}{|c|}{ Table 1. Causes of Fever } \\
\hline
\end{tabular}

Clinical presentation along with fever were malaise, chills, rigors, pain abdomen, burning micturition, diarrhoea, reduced or no foetal movement. Comorbidity in the form of anaemia, preeclampsia and gestational diabetes was found in $32.43 \%$ of women.

Among antenatal women, after treatment $56.66 \%$ $(n=102)$ of women were discharged in good foetal well-being condition and 12 women went LAMA (Leave against medical advice) in antenatal period, whereas in postnatal period eight women went LAMA. A total of $43.34 \%(n=78)$ women were delivered with $23.42 \%(n=42)$ vaginal delivery, $12.23 \%$ $(n=22)$ preterm vaginal delivery and $7.78 \% \quad(n=14)$ caesarean section. None of the women were induced for obstetrical indications (Fig. 1).

Around $12.23 \%(n=22)$ women landed up in preterm vaginal delivery and $6.11 \%(n=11)$ neonates required NICU care. However, all neonates were discharged in satisfactory conditions except one still birth. Two women with dengue had delivered macerated still born and expired in postpartum period. One of them had landed up in preterm vaginal delivery and the other one underwent caesarean section (Fig.1).

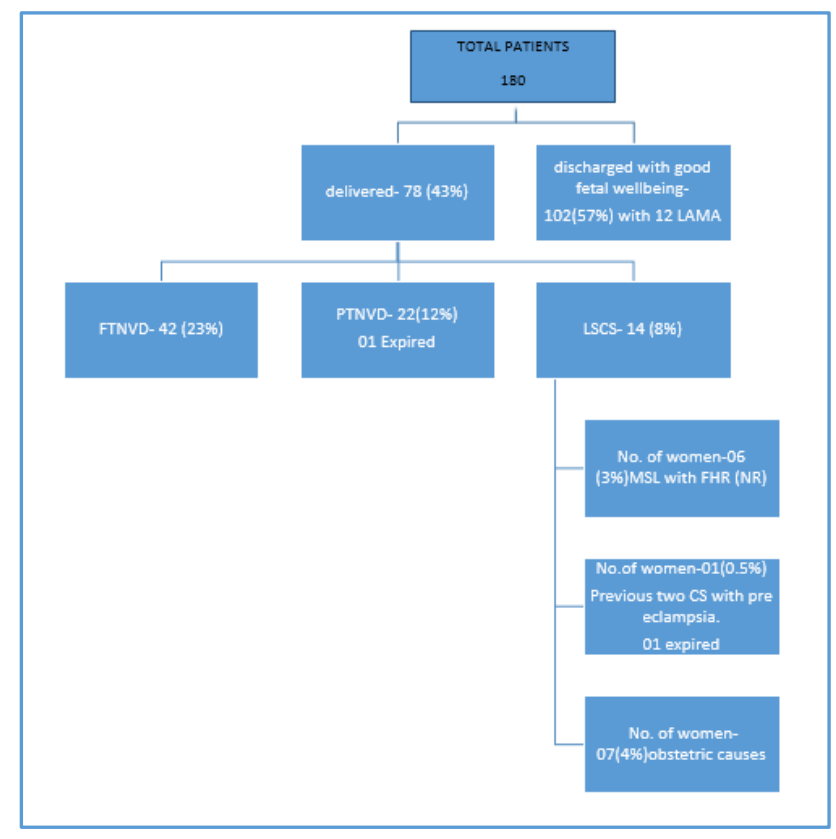

Figure 1. Distribution of Antenatal Women with Fever and its Outcome
Seventy two women (40\%) had temperature between 100 to 101 degrees Fahrenheit (F) and 63 women (35\%) had temperature range of 101 - 102 degrees $\mathrm{F}$ and rest had temperature below 100 degrees $\mathrm{F}$. There were fifty percent of women who had fever for 48 hours. Of $34.5 \%$ women having fever for more than 48 hours, $22.2 \%$ women had typhoid fever.

\section{DISCUSSION}

Fever is a defense mechanism against any infection in the body and it is difficult to distinguish the effects of fever from those of an underlying infection. Maternal fever is not uncommon during pregnancy, but the outcome can have varied pictures as it affects the health of both the mother and the foetus and increases the morbidity and mortality of both. The consequences depend on aetiology of fever and period of gestation at which infection occurs. Range and duration of fever are independent factors, which affects outcome. Pregnancy is a state of low immunity, hence any infection (viraemia or bacteraemia) can precipitate easily.

Studies reported that one in five women experience fever once in pregnancy. ${ }^{(1,2)}$ India being a tropical country with lots of diversity in weather leading to epidemic of many diseases. The study being conducted between June to September, which is the season of many epidemics in India.

All women in our study belonged to low socioeconomic group and from suburban area, which is per se indicative of lack of awareness and less availability of resources for the better well-being and so making them prone to many epidemic diseases.

There were $58.88 \%$ women in third trimester of antenatal period. Studies have shown the relation of fever in pregnancy with the birth defect in early trimester.(3,4) Edward et al found hyperthermia is a known cause of congenital defects of the central nervous system and other organs after sufficiently severe exposures during early organogenesis.(5) But in our study, most of the women were in the second or third trimester of pregnancy. So it was less likely that they will develop the congenital anomalies.

A surprising finding of $33.33 \%$ of women were with typhoid fever, which again emphasised the poor orofaecal route of contamination due to poor hygiene and low socioeconomic status, whereas it was rare in European countries.(6)

There were $22.2 \%(n=40)$ of women suffering from dengue and two women in this group had expired. It is the most fatal disease in our study group leading to mortality, which was also seen in the study by Swati et al.(7)

Study by Mac Grady R suggested that malaria is still the leading cause of fever in pregnancy, but we found only $5.56 \%$ $(n=10)$ women were suffering from malaria in our study group.(8)

There were $11.1 \%(n=20)$ who had UTI and five women underwent preterm labour. The study by Dimetry SR et al and Marziyeh A et al also showed the high incidence of preterm birth in women with UTI. $(9,10)$

A systemic review by Dreier showed that maternal fever during pregnancy may negatively affect offspring health.(11) Studies have been suggested that temperature more than 102 Fahrenheit and for a longer duration (more than 7 days) can lead to neural tube defect or infantile autism, but in our study only $10 \%$ of women with temperature more than 102 
Fahrenheit and none of them had fever for more than seven days.(12,13)

However, most of our women are in $2^{\text {nd }}$ or $3^{\text {rd }}$ trimester, but we do not have the follow-up, so we are not able to find long-term adverse effects on child as suggested by Dombrowski et al and by Calvani et al.(14,15)

Surprisingly, we found that $35 \%$ of patients who had fever went into labour and had vaginal delivery irrespective of the cause of fever. There were $12.23 \%$ women who landed up in preterm vaginal delivery and 11 babies required NICU care. The possible mechanism for this is due to the cascade of mediators released by active host inflammatory response to infection exerts distant effects on the uterus leading to preterm labour during the course of febrile illness due to viral or bacterial infections. On reviewing the literature, we did not find any study showing relation between fever and labour.

Limitation of the study was that it was for shorter duration and the result of study required long-term followup.

\section{CONCLUSION}

The common causes of fever in pregnancy in the present study were typhoid, dengue and viral fever, and dengue fever was the most fatal in all. Low threshold to admit these patients is mandatory and life saving for both mother and foetus. Vector control methods should be employed during seasonal outbreaks. Awareness programs and medical education programs on the management of foetal epidemic fever in pregnancy should be initiated, especially during outbreaks to provide quality care. Larger and increased duration studies in all gestational age are required to find out its sequels in pregnancy outcome.

\section{REFERENCES}

[1] Morken NH, Gunnes N, Magnus P, et al. Risk of spontaneous preterm delivery in a low-risk population: the impact of maternal febrile episodes, urinary tract infection, pneumonia and ear-nosethroat infections. Eur J Obstet Gynecol Reprod Biol 2011;159(2):310-14.

[2] Collier SA, Rasmussen SA, Feldkamp ML, et al. Prevalence of self-reported infection during pregnancy among control mothers in the National Birth Defects Prevention Study. Birth Defects Res A Clin Mol Teratol 2009;85(3):193-201.

[3] Li Z, Ren A, Liu J, et al. Maternal flu or fever, medication use and neural tube defects: a populationbased case-control study in Northern China. Birth Defects Res A Clin Mol Teratol 2007;79(4):295-300.
[4] Hashmi SS, Gallaway MS, Waller DK, et al. Maternal fever during early pregnancy and the risk of oral clefts. Birth Defects Res A Clin Mol Teratol 2010;88(3):18694.

[5] Edwards MJ. Review: hyperthermia and fever during pregnancy. Birth Defects Res A Clin Mol Teratol 2006;76(7):507-16.

[6] Carles G, Montoya Y, Seve B, et al. Typhoid fever and pregnancy. J Gynecol Obstet Biol Reprod (Paris) 2002;31(5):495-9.

[7] Sharma S, Jain S, Rajaram S. Spectrum of maternofetal outcomes during dengue infection in pregnancy: an insight. Article ID 5046091, Infect Dis Obstet \& Gynecol 2016;2016: p. 4.

[8] McGready R, Ashley EA, Wuthiekanun V, et al. Arthropod borne disease: the leading cause of fever in pregnancy on the Thai-Burmese border. PLoS Negl Trop Dis 2010;4(11):e888.

[9] Dimetry SR, El-Tokhy HM, Abdo NM, et al. Urinary tract infection and adverse outcome of pregnancy. J Egypt Public Health Assoc 2007;82(3-4):203-18.

[10] Amir MI, Lavasani Z, Norouzirad R, et al. Prevalence of urinary tract infection among pregnant women and its complications in their newborns during the birth in the hospitals of Dezful City, Iran, 2012-2013. Iran Red Crescent Med J 2015;17(8):e26946.

[11] Dreier JW, Andersen AM, Berg-Beckhoff G. Systematic review and meta-analyses: fever in pregnancy and health impacts in the offspring. Pediatrics 2014;133(3):e674-88.

[12] Chambers CD, Johnson KA, Dick LM, et al. Maternal fever and birth outcome: a prospective study. Teratology 1998;58(6):251-7.

[13] Atladóttir HÓ, Henriksen TB, Schendel DE, et al. Autism after infection, febrile episodes and antibiotic use during pregnancy: an exploratory study. Pediatrics 2012;130(6):e1447-54.

[14] Dombrowski SC, Martin RP, Huttunen MO. Association between maternal fever and psychological/behavior outcomes: a hypothesis. Birth Defects Res A Clin Mol Teratol 2003;67(11):905-10.

[15] Calvani M, Alessandri C, Sopo SM, et al. Infectious and uterus related complications during pregnancy and development of atopic and non-atopic asthma in children. Allergy 2004;59(1):99-106. 